\title{
TÉRMINOSY CONCEPTOS PARA LA DESCRIPCIÓNY CARACTERIZACIÓN DE SITIOS $Y$ CONTEXTOS CON RESTOS HUMANOS Y ELEMENTOS ASOCIADOS EN ARQUEOLOGÍA FORENSE
}

\author{
FlaVio ANTONIO ESTRADA MORENO \\ Instituto de Medicina Legal y Ciencias Forenses del Ministerio Público \\ flavio_estrada@hotmail.com
}

\section{RESUMEN:}

El presente artículo propone una serie de conceptos a fin de establecer una terminología útil para la descripción y caracterización de contextos arqueológico forense producidos tanto en casos de graves violaciones a los derechos humanos como en casos comunes. No tiene la pretensión de ser un producto acabado y este podrá, y deberá, ser mejorado o simplemente desechado en la medida que su contraste con la realidad así lo determine.

Palabras claves: Arqueología funeraria, arqueología de la muerte, arqueología forense, restos humanos, elementos asociados, violencia interna.

\section{AbStRact:}

The present article proposes a series of concepts to establish a useful terminology for the description and characterization of archaeological forensic contexts produced by Human Rights Violations and common cases. It does not claim to be a finished product and this may, and should, be improved or simply discarded to the extent that its contrast with reality so determined.

Keywords: Funerary archaeology, archaeology of death, forensic archeology, human remains, associated elements, internal violence. 


\section{INTRODUCCIÓN}

La muerte ${ }^{1}$ de una persona en situaciones normales, es sin lugar a dudas un hecho individual pero su disposición final, aun aquellas que desde nuestro punto de vista las podríamos calificar como muy simples o muy pobres, es un hecho social ya que serán otras personas quienes la lleven a cabo implicando un acto social enmarcado por las creencias y los requerimientos sociales (Andrés 2003) existentes en un tiempo y en un espacio determinado. Durante los años que llevamos a cabo la recuperación de restos humanos y elementos asociados hemos tenido la oportunidad de enfrentarnos a contextos funerarios que tienen un interés forense (Estrada 2013). Y es allí en donde pudimos observar la intencionalidad en la disposición del cadáver por parte del entorno social al cual pertenecía el fallecido. Hemos registrado información oral e información contextual de actividades que tienen que ver con la propia práctica funeraria (lavar el cadáver, vestirlo), con la práctica sepulcral (elección del espacio físico, depósito del cadáver y de los elementos asociados), y algunas prácticas postsepulcrales (recolección de huesos) todas ellas acciones intencionales y estructuradas de deposición ${ }^{2}$ de los muertos configurando lo que se conoce como gesto funerario (Quintana y Alesan 2003). Pero los muertos además cohesionan a los integrantes de una o más comunidades en tanto ellos reconozcan al o los fallecidos como un ancestro en común que los vinculen. El desarrollo de los rituales funerarios consolida y prolonga la cultura ya que tales actividades no sólo tratan con el cuerpo del difunto sino también con su alma y con sus familiares ¿Pero qué sucede cuando esas personas muertas en situaciones anormales como una guerra interna no son dispuestas por sus familiares, amigos y vecinos? Dicen en Ayacucho que cuando una persona muere de manera violenta su "almita" vagará por los parajes atemorizando y asustando a todo aquel, humano o animal, que pase cerca de allí ya que estará en una pena constante. Pero esa muerte violenta no sólo condena al alma sino también condena a sus familiares a un luto permanente ante la constante ausencia del familiar desaparecido. Es un ciclo de duelo constantemente inacabado que altera la regularidad no solo de la familia sino de la comunidad.

El conflicto armado interno ocurrido en el Perú durante los años 1980 al 2000 dejó un número aproximado de entre 13,000 a 15,000 peruanas y peruanos desaparecidos. Esta violencia desatada entre los distintos actores dio origen a la formación de distintos sitios con restos humanos y elementos asociados a lo largo y ancho de todo el país.

Diversas publicaciones y arqueólogos tanto nacionales como extranjeros, algunos de los cuales participaron inicialmente en las investigaciones forenses en el Perú , usaban términos imprecisos para describir el contexto de manera tal que al lado de conceptos como "fosas" encontramos "sitios primarios" y "sitios secundarios" en donde las características que debían ser atribuidas al contenido eran dadas al continente o receptáculos (Fondebrider 2001, CVR 2003) y otros que no son claras en su definición (Jesee \& Skinner 2005, Bacigalupo 2005). De la misma manera el término "entierro" fue sinónimo de individuo humano y usado indistintamente ya sea que este se encontraba depositado al interior de un nicho, al interior de una fosa o dejado en superficie. El problema también se presenta cuando se trata de usar términos de uso común en la arqueología funeraria, la mayoría de ellos referidos a restos humanos que se encontraban enterrados (Brothwell 1987, Ravines 1989, Aliaga 2012, Duday 1997) , a lo que se suma el uso de términos establecidos originalmente en lengua inglesa traducidos y trasladados a la arqueología forense.

1. La muerte, el cese de la vida, debe ser visto como un proceso y no como un evento. La vida no se extingue al mismo tiempo en cada uno de los tejidos (Vargas-Alvarado 1991). La muerte es una cadena de modificaciones cuya característica singular es la irreversibilidad (Trezza 2006). término hace alusión a la evacuación de los intestinos. A lo largo del presente texto no volverá a ser usado. 
Tal como señalan Jessee y Skinner ${ }^{3}$ (2005) la preocupación del arqueólogo tiene que ver con el reconocimiento, documentación e interpretación sobre los procesos de formación de los sitios y su efecto en los restos humanos y elementos asociados así como reconstruir el comportamiento de los perpetradores y sus cómplices. Señalan así mismo la carencia de un protocolo de campo arqueológico internacionalmente estandarizado, y la falta de una investigación científica relacionada al entendimiento y análisis de estos sitios, así como una falta de comunicación y publicación e intercambio de conocimiento entre expertos en la materia. Finalmente señala que deben tomarse los pasos iniciales con el fin de proveer terminología estandarizada para clasificar las diversas variedades de fosas masivas y de sitios relacionados con fosas masivas. Ya que finalmente la evidencia física tiene un rol en el refuerzo o rechazo de cualquier información basado en los testimonios de los informantes.

En general las recurrencias en la cantidad de los cadáveres depositados y las relaciones espaciales de los elementos asociados, el tiempo en que estos se produjeron, la posición y orientación de los individuos permiten establecer patrones de tratamiento pre, peri y posterior al depósito y proporcionar valiosa información de tipo cultural o acerca la muerte del individuo y los perpetradores mismos.

\section{El Sitio con Restos Humanos y Elementos Asociados}

Un sitio con restos humanos y elementos asociados es el producto materializado de un complejo proceso dinámico en el cual interactúan factores naturales y humanos que determinan y configuran la imagen final, y aparentemente estática, del contexto arqueológico forense al momento de su intervención. Este sitio es el punto de partida del estudio arqueológico. Lo definimos como una localización espacial y temporal de actividad humana del pasado inmediato a las que se añaden las acciones no antrópicas producidas a lo largo del tiempo y que han generado una modificación observable en el espacio y están relacionados a graves violaciones a los derechos humanos o violencia común. Estos sitios son diferentes entre sí y pueden ser clasificados considerando la dimensión, el contenido, antigüedad, estado de conservación, etc. (Estrada 2012). De acuerdo al espacio físico que ocupan los restos humanos y elementos asociados estos sitios pueden subdividirse en:

Sitio con restos humanos y elementos asociados enterrados: uno o más individuos son depositados al interior de una fosa o zanja y luego cubierto con material de desmonte constituyendo el relleno del hoyo.

Sitio con restos humanos y elementos asociados en superficie: Puede corresponder a casos en que el individuo humano fue dejado en la superficie del sitio o producto de las disturbaciones postdeposicionales de manera tal que los restos humanos quedaron expuestos. Mediante una correcta excavación y recolección de los restos se establecerá si el individuo fue enterrado o fue dejado en la superficie del sitio.

Sitio con restos humanos y elementos asociados en estructuras funerarias: El individuo fue colocado dentro de un nicho, tumba o sepulcro.

Sitios mixtos: Un mismo sitio puede presentar restos humanos y elementos asociados tanto enterrados como en estructuras funerarias tal como ocurre en un cementerio.

3. Jessee y Skinner (2005) señalan que una fosa masiva es cualquier lugar que contiene dos o más cuerpos asociados, colocados de manera indiscriminada o deliberada, los cuales pertenecen a víctimas que han muerto como resultado de confrontaciones armadas o catástrofes mayores conocidas. 


\section{Los Componentes de un Contexto Arqueológico Forense}

Un contexto arqueológico forense se encuentra constituido por los siguientes elementos:

El espacio físico: Es el espacio en donde quedaron depositados los restos humanos y sus elementos asociados. Estos espacios pueden ser naturales (cuevas, suelo) o artificiales (estructuras funerarias, fosas, pisos) o una combinación de ambos espacios. Adicionalmente cuando se trata de fosas se añadirá como elemento adicional a el relleno el cual es el material de origen geológico y que puede provenir del propio desmonte producto de la excavación pudiendo también provenir de suelos culturalmente estériles o con presencia de restos culturales tanto antiguos como modernos o una mezcla de ambos y que llena el espacio al interior de la fosa (Kaulicke 1997). La descripción tanto de la matriz como del relleno debe realizarse en los siguientes aspectos: color, textura, naturaleza de los componentes, estructura, consistencia y grado de densidad.

El Individuo: Es la parte esencial del contexto arqueológico forense. El individuo 4 humano es una unidad biológica y cultural que se encuentra contenido en el espacio físico. Kaulicke (1997:25) señala que "el término es más neutral debido a que no se refiere a un estado particular".

Los elementos asociados: Son todos aquellos objetos tanto de origen natural o antrópico que se encuentran en relación directa con el individuo e indican que fueron depositados en el mismo espacio de tiempo.

\section{Documentación de CAMPo}

La codificación del sitio y del individuo

La nomenclatura ${ }^{5}$ asignada tanto al sitio como al individuo o restos humanos está constituida por letras y números que hacen referencia a su ubicación política. En casos de que se trate de nombres compuestos se pondrán las iniciales seguidos de un punto. Esta nomenclatura consta de los siguientes niveles:

a).El primer nivel establecerá la localización política mediante tres primeras letras que hacen referencia al nombre del departamento, provincia, distrito.

b).El segundo nivel de la nomenclatura corresponde al número correlativo asignado a las presuntas fosas, tumbas o nichos que se encuentren al interior del sitio. Esta expresión alfanumérica podrá representar también al sector en caso necesario.

c). El tercer nivel de la nomenclatura se encuentra constituido por letras y números después de un guión y corresponderá al individuo y sus elementos asociados.

Una vez establecido la nomenclatura durante la etapa de recuperación y/o exhumación esta deberá ser mantenida, aún cuando se le adicionen otras nomenclaturas como el Protocolo de Necropsia (PN), hasta el almacenamiento final de las evidencias.

4. Un humano es considerado como un animal biocultural que ha desarrollado cultura como una estrategia de adaptación para sobrevivir y por lo tanto se convirtió en humano (Jurmain et al 1987). Se conoce como cadáver al cuerpo humano en el que se haya comprobado la perdida de la vida (Vargas Alvarado 1991).

5. En arqueología se usa las categorías de Sitio, sector, unidad.

6. http://www.iso.org/iso/home/standards/country_codes.htm 


\begin{tabular}{|c|c|c|c|c|c|c|c|c|c|}
\hline \multirow{2}{*}{01} & Amazonas & \multirow{2}{*}{06} & Cajamarca & \multirow{2}{*}{11} & Ica & \multirow{2}{*}{16} & Loreto & \multirow{2}{*}{21} & Puno \\
\hline & PE-AMA & & PE-CAJ & & PE-ICA & & PE-LOR & & PE-PUN \\
\hline \multirow[b]{2}{*}{02} & Ancash & \multirow[b]{2}{*}{07} & Callao & \multirow[b]{2}{*}{12} & Junín & \multirow[b]{2}{*}{17} & Madre de Dios & \multirow[b]{2}{*}{22} & San Martín \\
\hline & PE-ANC & & PE-CAL & & PE-JUN & & PE-MDD & & PE-SAM \\
\hline \multirow[b]{2}{*}{03} & Apurímac & \multirow[b]{2}{*}{08} & Cusco & \multirow[b]{2}{*}{13} & La Libertad & \multirow[b]{2}{*}{18} & Moquegua & \multirow[b]{2}{*}{23} & Tacna \\
\hline & PE-APU & & PE-CUS & & PE-LAL & & PE-MOQ & & PE-TAC \\
\hline \multirow[b]{2}{*}{04} & Arequipa & \multirow[b]{2}{*}{09} & Huancavelica & \multirow[b]{2}{*}{14} & Lambayeque & \multirow[b]{2}{*}{19} & PASCO & \multirow[b]{2}{*}{24} & Tumbes \\
\hline & PE-ARE & & PE-HUV & & PE-LAM & & PE-PAS & & PE-TUM \\
\hline \multirow[b]{2}{*}{05} & Ayacucho & \multirow[b]{2}{*}{10} & Huánuco & \multirow[b]{2}{*}{15} & Lima & \multirow[b]{2}{*}{20} & PIURA & \multirow[b]{2}{*}{25} & Ucayali \\
\hline & PE-AYA & & PE-HUC & & PE-LIM & & PE-PIU & & PE-UCA \\
\hline
\end{tabular}

Figura 01: De acuerdo a la norma ISO6 3166 las dos primeras letras representan el nombre del país (Ejemplo: Perú= PE) luego del guión se colocan las tres primeras letras correspondientes al nombre del departamento (Ejemplo: Ayacucho= AYA). Básicamente tiene el objetivo de que mediante tales letras podamos fácilmente reconocer la procedencia de los restos humanos y elementos asociados. Por otro lado los números que van del 01 al 25 corresponden al ubigeo 7 del INEI asignado a cada uno de los departamentos del Perú.

Debido a que la actividad arqueológica es una práctica destructiva y que los sitios son intervenidos por primera y única vez es importante llevar a cabo un adecuado registro escrito, gráfico y fotográfico del contexto arqueológico forense. Bajo este concepto se debe registrar la posición que tomó el individuo al quedar depositado dentro del espacio físico y debe ser descrito en relación a su esqueleto axial y esqueleto apendicular, y la orientación del individuo que se encuentra en relación a un punto geográfico o cultural de referencia que tomó el cuerpo al momento de ser depositado al interior de la estructura funeraria, fosa o quedar en superficie. Tanto la posición como la orientación que presenta un individuo pueden proporcionar información muy valiosa ya sea esta de tipo cultural o sobre la muerte misma del individuo. De la misma manera todos los huesos y sus elementos asociados deben ser registrados en sus tres dimensiones usando para ello un punto de referencia.

\section{DESCRIPCIÓN DE LOS INDIVIDUOS}

\section{Posición del individuo}

De acuerdo a Ubelaker (2003) posición es la configuración que adopta el cuerpo sobre el terreno. Para Sprague (2005) posición se refiere a las relaciones de las partes del cuerpo entre si. La posición no tiene nada que ver con la tumba o contenedor o al eje de la tierra, puntos cardinales o cualquier otro atributo natural sino que involucra sólo el cuerpo. Los puntos del cuerpo son el tronco hasta los muslos o articulación de la cadera, los muslos a la pierna o la rodilla, la posición de los brazos en relación con el tronco y la cabeza al tronco del cuerpo en la unión del cuello. La posición debe ser pensada como si el cuerpo estuviese suspendido en el espacio. Posición ${ }^{8}$ es la posición del cuerpo.

Para describir la postura del individuo en el espacio físico en donde se encuentra es necesario registrar la posición que toman tanto el esqueleto axial y el esqueleto apendicular y ambas ser descritas de manera separada. La posición es descrita mejor en referencia a tres componentes anatómicos: (1) Huesos del muslo y de la pierna (fémur, tibia y peroné respectivamente), (2) Huesos del brazo y del antebrazo (Húmero, radio y cúbito respectivamente) y (3) la cabeza (cráneo). A fines de evitar ambigüedades en la descripción esta debe ser complementada con un gráfico y con un detallado registro fotográfico (Ubelaker 2003). 
El esqueleto 9 axial comprende a los huesos del cráneo y tronco por su parte el esqueleto apendicular se refiere tanto a los huesos de las extremidades superiores como a las extremidades inferiores las cuales incluyen las cinturas pélvica y escapular (White \& Folkens 2005)

\section{Posición del esqueleto axial}

En el presente texto usaremos el término decúbito una palabra de uso común dentro del contexto médico legal (Ministerio de Justicia y Derechos Humanos 2013) y el cual hace referencia a la posición del cadáver.

El decúbito es la postura ${ }^{1}$ que toma el cuerpo cuando este se encuentra acostado, tumbado o yacente. Las variedades se establecen en función a las superficies anatómica del esqueleto axial que entran en contacto, por lo general, con el plano horizontal sobre el cual se apoya al momento de ser depositado en la fosa, la estructura funeraria o quedar en superficie. Las variedades en la posición que toma el eje axial pueden ser las siguientes:

a) Decúbito dorsal: La superficie dorsal (espalda) del individuo se encuentra en contacto con el plano horizontal en el cual se apoya. Se le conoce también como "boca arriba".

b) Decúbito lateral: Un lado del individuo (derecho o izquierdo) que se encuentra en contacto con el plano horizontal en el cual se apoya. Se le conoce también como "de lado".

c) Decúbito ventral: Las superficies ventral y torácica del individuo se encuentran en contacto con el plano horizontal en el cual se apoya. Se le conoce también como "boca abajo".

d) Sedente: Isquiums y sacro del individuo se encuentran apoyados en el plano horizontal mientras que parte de la columna vertebral se encuentra apoyado en un plano vertical. Se le conoce también como "sentado".

\section{Posición del esqueleto apendicular (huesos de los miembros superiores e inferiores).}

La posición del esqueleto apendicular es la relación de los huesos tanto de los miembros superiores como inferiores con el eje axial del individuo. Es mejor describir los huesos de cada segmento tanto de los miembros superiores como inferiores de manera separada. Los huesos de los miembros inferiores pueden ser descritos de la siguiente manera:

Mientras que los huesos de los miembros superiores pueden ser descritos de la siguiente manera:

Si los miembros superiores o inferiores se alejan o acercan al plano medio se emplearan los siguientes términos:

Una mención especial merecen los huesos de las manos. Estas pueden encontrarse cruzados (indicando cuál es la mano que se superpone a la otra), sobre, debajo o a los lados de la pelvis, cruzados sobre el pecho, sobre el esplacnocráneo, debajo o a los lados del cráneo. Ambas deben ser descritas de manera separada. Los huesos de las manos pueden presentarse flexionados (en puño) o extendidos. Sprague (2005) señala que existen cinco posiciones básicas de los brazos y antebrazos o una combinación de estas. Estas posiciones son las siguientes:

Extendido a lo largo de los lados.

Manos sobre la pelvis.

1. Sprague (2005) la define como disposición (deposition) que es la manera en la que el individuo ha quedado expuesto o enterrado. 
Manos sobre el pecho (en actitud de orador).

Manos sobre el hombro opuesto

Manos a la cara.

Envueltos alrededor de las piernas (limitado a entierros flexionados).

\section{Orientación del individuo}

Es la dirección que toma el eje axial (cráneo-caudal) con respecto a un punto geográfico o cultural de referencia. Se debe especificar la orientación que toma el esplacnocráneo. Para ello el registro gráfico y fotográfico debe contar con un norte gráfico establecido con una brújula. Sprague (2005) señala que la orientación puede ser dada en términos de grados o azimut, puntos cardinales y sus subdivisiones o en términos de alguna característica natural.

\section{Profundidades a las que se encuentra el individuo}

Es importante registrar las profundidades a las que se encuentran los siguientes puntos: centro del cráneo, hombro izquierdo/derecho, codo izquierdo/derecho, muñeca izquierda/ derecha, sínfisis púbica, rodilla izquierda/derecha, tobillos izquierdo/derecho. Estas medidas deben ser tomadas a partir de un punto estable de referencia usando un cordel, un nivel de pita y una wincha métrica.

\section{La descripción del espacio físico}

Tal como habíamos señalado líneas arriba el espacio físico puede ser natural o artificial o una combinación de ambos. En cualquiera de los casos es importante registrar la forma, sus dimensiones (largo, ancho, profundidad, y de ser el caso el área de dispersión) y la materia prima que se uso para construirlo y de ser posible establecer las herramientas con la que fue elaborada. De tratarse de un contexto funerario a los datos arriba mencionado se les debe añadir el de la alineación ${ }^{2}$ el cual atañe únicamente a la tumba o contenedor (Sprague 2005). Entre los usuales contenedores se encuentran los ataúdes (cajas mortuorias de metal o madera de forma rectangular en los estilos más modernos y de forma trapezoidal para los más antiguos) También existen los falsos ataúdes elaborados con listones de madera que rodean al individuo definiendo una especie de marco sobre los cuales se colocan mas listones de madera para construir este ataúd. Los cadáveres pueden encontrarse también con envoltorios (textiles o bolsas de plástico que envuelven total o parcialmente al individuo) o con cobertores (textiles o bolsas de plástico que cubren total o parcialmente al individuo).

\section{La descripción de los elementos asociados}

Los elementos asociados ya sean de origen natural o antrópicos deben ser registrados en relación a la proximidad anatómica del individuo indicando sus características más notables. Usualmente se encontrarán vestimentas por lo que es importante distinguir entre ropa asociada y ropa puesta. A lo largo del tiempo la materia prima con la que se elaboran las prendas han pasado desde las fibras naturales (de origen vegetal o animal) hasta las fibras sintéticas estas últimas son resistentes a los agentes medioambientales y en muchos casos ayudan a la conservación y evitan la dispersión de los restos. Por su parte las fibras naturales se desintegran rápidamente conjuntamente con la descomposición del individuo dando la falsa impresión de que estamos ante un cadáver que fue dispuesto completamente desnudo. Casquillos y proyectiles de arma de fuego, instrumentos punzo-cortantes y contusos pueden ser también encontrados conjuntamente con los restos humanos.

2. La alineación es la orientación que toma la estructura funeraria. 


\section{El registro fotográfico}

Para que el registro fotográfico sirva como medio probatorio este deberá llevar los siguientes elementos: a) El código asignado tanto al sitio con restos humanos como el código asignado al individuo. Para ello una pizarra acrílica o pizarra para tiza de tamaño A4 resultan siendo los más útiles. B) Norte gráfico colocado a un lado del individuo. La longitud de este elemento no debe ser mayor a $30 \mathrm{~cm}$. C) Escala gráfica con una longitud total de 1 metro dividido en segmentos de $10 \mathrm{~cm}$ cada uno intercalando un segmento blanco y otro segmento negro. En lo posible colocar también una escala gráfica vertical para registrar la profundidad a la que se encuentran los restos humanos y elementos asociados. En general es importante tener en consideración que los elementos señalados no "compitan" con el individuo a registrar.

\section{Demografía}

Edad al momento de la muerte (edad biológica, edad fisiológica)

La edad cronológica es el tiempo transcurrido desde el nacimiento del individuo hasta completar un año a la hora y día de su nacimiento o de su muerte o de su desaparición. Esta edad se expresa en años, meses, días. Por otro lado se encuentra la edad al momento de la muerte y que fisiológicamente se establece en base a dos parámetros: a) Crecimiento y desarrollo, b) Cambios degenerativos. Es importante recalcar que ya sea que se estime la edad por uno u otro parámetro este indica que el individuo se encontraba en un estadio y esta no expresa por ningún motivo la edad cronológica del individuo. De acuerdo a la experiencia del investigador se podrán emplear las siguientes categorías:

\section{Sexo biológico y género}

Un error común dentro del análisis de restos humanos es usar los términos sexo y género como sinónimos. El sexo se encuentra determinado genéticamente mientras que género es un constructo social basado en diferencias del sexo. Mientras que el sexo se estima en base al análisis de los restos óseos el género se puede estimar en base al estudio de la cultura material y al contexto (White 2005). Las categorías a usar son las siguientes:

\section{Caracterización de los Contextos}

La caracterización de los contextos permite reconstruir la historia deposicional y postdeposicional que se originó al interior del sitio con restos humanos. Un término que creemos más apropiado para ser usado es el de depósito. Este término, procedente originalmente de la geología, hace alusión a él conjunto de elementos acumulados producidos de manera intencional o inintencional tanto por agentes antrópicos como por agentes medioambientales y/o biológicos no humanos o una combinación de todos ellos. El depósito forense ${ }^{17}$ se compone de los restos del individuo y de los elementos asociados dispuestos en el espacio físico determinado. Este término puede ser aplicado a describir las características del contexto ya sea que se trata de restos humanos que fueron depositados al interior de estructuras funerarias, enterrados o dejados en superficie. Bajo este término y basado en los aportes de Duday (1997), Kaulicke (1997), Roksandic (2002), Fondebrider \& Mendoza (2002), Ubelaker (2003), Sprague (2005), Komar \& Buikstra (2008) proponemos la siguiente caracterización:

\section{a) SEGÚN EL NÚMERO DE INDIVIDUOS:}

Depósito individual: Cuando los restos humanos y elementos asociados existentes corresponden a un sólo individuo. 
Depósito colectivo (múltiple): Cuando los restos humanos y elementos asociados corresponden a más de un individuo. Cada uno de ellos se encuentra relativamente separado y dispuesto de manera ordenada. De acuerdo a Komar \& Buikstra (2008) cuando se trata de un contexto de este tipo se puede observar que los individuos fueron colocados de manera ordenada con el suficiente espacio entre ellos, las cabezas orientadas en una misma dirección y por lo general en posición decúbito dorsal. Por su parte Sprague (2005) señala que un entierro múltiple consiste de varios cuerpos articulados ${ }^{18}$ y que el orden es más común en este tipo de entierros.

Depósito masivo: Cuando los restos humanos corresponden a más de un individuo. A diferencia del depósito colectivo aquí los individuos se encuentran mezclados entre ellos de manera desordenada. De acuerdo a Komar \& Buikstra (2008) cuando se trata de un contexto de este tipo los individuos se encuentran mezclados entre ellos ya que usualmente los individuos han sido lanzados en el lugar ya sea manualmente o usando maquinaria pesada. Por su parte Sprague (2005) señala que un entierro masivo consiste de cuerpos desarticulados o solamente de fragmentos articulados y que el caos es más común en este tipo de entierros.

\section{b) SEGÚN EL ESTADO EN QUE SE HALLE:}

Depósito primario: Es aquella en que los restos humanos han permanecido en el mismo lugar de donde son recuperados. Duday (1997) señala que en estos lugares los cadáveres frescos son colocados poco después de la muerte y es en donde se producirá la descomposición total del cuerpo. En general se caracteriza por que los restos conservan sus relaciones anatómicas. Sin embargo tal como señala Roksandic (2002) no se puede inferir una disposición primaria sólo porque todos los elementos esqueléticos están presentes en orden anatómico. Los cuerpos pueden ser removidos cuando todavía conservan tejido blando en descomposición sin presentar por ello desarticulación. Los cuerpos pueden también ser movidos desde una posición primaria mientras se encuentran envueltos con algún elemento o dispuestos dentro de algún tipo de ataúd o cofre.

Duday (1997) señala que es preciso demostrar que las estructuras orgánicas como piel, tendones, aponeurosis y ligamentos aún eran los bastante sólidas como para impedir la separación de dos huesos contiguos.

Depósito secundario: son aquellas en que los restos, luego de su depósito original, son retirados y vueltos a depositar en un lugar distinto. Los restos no conservan las relaciones anatómicas, siempre y cuando el cadáver se encuentre en avanzado estado de descomposición, observándose además la ausencia de algunos huesos. Roksandic (2002) señala que mucha precaución debe ser usada en deducir disposición secundaria simplemente porque algunos elementos esqueléticos están en desarreglo o cuando esqueletos completos no están presentes. Tales disturbaciones pueden ser causados por una variedad de agentes. Sin embargo las disposiciones secundarias son descritas tradicionalmente como conteniendo esqueletos completos con algunos elementos en desarreglo anatómico, tales generalizaciones son útiles solamente en casos de buena preservación. Un valioso indicador de disposiciones secundarias es la baja representación de elementos normalmente bien preservados.

17. Se incluye aquí también el depósito funerario que tiene algún interés forense.

18. Sprague (2005) señala que articulado es cuando los restos esqueléticos se encuentran en el orden anatómico normal. Mientras que desarticulado significa que no se encuentra articulado y por lo tanto no se encuentra en el orden anatómico normal. Por nuestra parte entendemos que articulado es cuando los restos aun presentan tejidos blando uniendo los segmentos corporales. 
Deposito terciario: Son aquellos en que los restos luego de su depósito original son retirados, ya sea en incipientes o avanzados estados de descomposición o esqueletización y llevados a un lugar en donde reciben un tratamiento especifico, usualmente la incineración, y luego los restos (carbonizados y/o calcinados) son depositados en un nuevo lugar.

Depósito disturbado: es aquel que en algún punto ha sido alterado después de su depósito (el cual puede ser primario, secundario o terciario) inicial pero no necesariamente movido a un nuevo lugar. En muchos casos, unos pocos elementos esqueléticos pueden estar desarticulados 1 o perdidos mientras que los restantes elementos están preservados en su posición anatómica original. Esta disturbación puede deberse a agentes bióticos como carnívoros perros, cerdos, roedores o al movimiento de las raíces, se encuentran también los agentes geológicos como los movimientos naturales del terreno y finalmente los agentes antrópicos cuya acción intencional o inintencional disturba los depósitos.

\section{c) SEGÚN ESPACIOS TEMPORALES:}

Depósito sincrónico: son aquellas en que los cuerpos son depositados todos en un mismo suceso temporal (simultáneos). Rocksandic (2002) propone a su vez que esta forma de disponer de los cadáveres puede ser:

Depósito sincrónico primario: Mas de un individuo depositado al mismo tiempo en un mismo lugar.

Depósito sincrónico secundario: Como en el caso de un osario, ésta última requiere que todos los difuntos se hayan descompuesto en otro lugar y fueran luego re-depositados en el mismo tiempo prescrito con respecto al estado de la descomposición. Esto podría causar una muy amplia variedad de patrones: algunos de los huesos pueden estar prolijamente, pero artificialmente, arregladas mientras otros pueden exhibir conexiones anatómicas totalmente preservadas como en un entierro primario (Roksandic 2002).

Depósito diacrónico: Son aquellas en que los individuos son depositados en diferentes sucesos temporales, es decir, que el espacio es reutilizado (Fondebrider 2001). En el caso de sucesivos depósitos es necesaria abrir un acceso ya sea a la tumba, fosa, o nicho. Los osarios diacrónicos podrían diferir de algunos sincrónicos por la gran uniformidad del grado de descomposición (Rocksandic 2002).

Deposito diacrónico primario: Los individuos (usualmente completos) son depositados sucesivamente en un mismo lugar.

Depósito diacrónico secundario: Los individuos (o los restos humanos) son depositados sucesivamente en el mismo lugar, que es reutilizado luego de que los restos estuvieron dispuestos inicialmente en otro sitio. La sincronía del depósito final no implica la sincronía de la muerte ya que los individuos depositados pueden ser traídos después de un intervalo de tiempo.

1. Algunas características tafonómicas permiten establecer la existencia dentro del espacio físico de huesos de tamaño pequeño perteneciente a articulaciones lábiles (que se extinguen rápidamente) entre las que se encuentran las falanges, metacarpos, carpos, metatarsos y tarsos que por lo general no se recogen debido a su pequeño tamaño y cuando el individuo se encuentra en avanzado estado de descomposición. Pueden estar presentes en depósitos disturbados pero raramente en depósitos secundarios pese a ello su ausencia tampoco puede ser tomada como indicador infalible dependiendo en todo caso a factores de conservación diferencial de los huesos (Aliaga 2012). 


\section{El Tratamiento del Individuo Previo a su Depósito Final}

Se establecen dos tipos de tratamientos de acuerdo a su intencionalidad:

Tratamiento funerario: Se encuentra en relación a prácticas funerarias existentes en un determinado tiempo y lugar. Se incluye aquí el lavado y vestido del cadáver ya sea con ropa de uso funerario (como hábitos) o con la ropa que usualmente vestía el individuo. La posición en decúbito dorsal, con las manos cruzadas a nivel de la sínfisis púbica o a los lados de la cintura pélvica caracteriza a las prácticas funerarias católicas. Posición y orientación del individuo así como la alineación de la estructura funeraria señaladas líneas arriba se relacionan al tratamiento funerario.

Tratamiento no funerario:

a) Tratamiento criminal: La cremación de cadáveres en diferentes estados de descomposición y el seccionamiento de cadáveres frescos con fines de su desaparición son prácticas registradas en el contexto peruano.

b) Tratamiento no criminal: Se incluye aquí el proceso de necropsia el cual consiste en la apertura de las cavidades craneal, toraxica y abdominal. El cráneo es aperturado mediante el aserrado en su diámetro transverso en tanto que en el tórax se podrá apreciar la separación del peto esternal seccionado a nivel de la unión costocondral y retirado del esternón desarticulándolo de la clavícula. Como elemento asociado se podrá registrar la presencia de un hilo grueso de cordel o pabilo que cierra todas cavidades a través de puntadas en el tejido blando. La forma más común de la apertura de las cavidades torácica y abdominale es mediante un corte desde el cuello hasta la sínfisis púbica conocido como corte en "I". Otras formas menos comunes son las "Y" y la "U". Otros tratamientos de los cadáveres incluye el "embalsamamiento" que en nuestro país consiste en aplicar inyecciones de alcohol industrial o formaldehido tanto en tórax como en abdomen así como colocarle pequeños paquetes de algodón en fosas nasales, cavidad bucal y conductos auditivos externos. En tratamientos más complejos se encuentra la evisceración de algunos órganos como los intestinos delgado y grueso ya que contienen heces fecales y es en donde se inicia el proceso de descomposición.

\section{Estimación del Intervalo Postmortem}

El intervalo postmortem conocido en términos médico legales como "data de muerte" o antiguamente con el complejo nombre de "cronotanatodiagnóstico" es el tiempo que transcurre desde la muerte del individuo hasta su hallazgo o recuperación. Una vez que las funciones vitales cesan se inicia el proceso de descomposición. La putrefacción es la destrucción del tejido por acción de las bacterias, siendo aquellas que se encuentran en el tracto intestinal la fuente principal. La descomposición se acelera en un medio ambiente caluroso (Di Maio 2003) y húmedo como la costa y se retarda en un ambiente frio y seco como ocurre en la sierra. Aceleran o retardan el proceso los factores intrínsecos (del propio individuo) o extrínsecos (del medio y de la acción que se ejerza sobre el individuo). Por otro lado se encuentra la esqueletización que es la remoción del tejido blando. Esta puede ser considerada completa si todos los tejidos blandos han sido removidos o parciales si algunas porciones del hueso se encuentran expuestas. La desarticulación generalmente procede desde la cabeza hacia abajo con la mandíbula separándose del cráneo y la cabeza de la columna vertebral y desde el centro a la periferia y desde la Columba vertebral a las extremidades (Clark et al 1996). El denominado periodo reductivo es la parte final que concluirá con la total reducción del cadáver en un proceso que puede durar varios años (Trezza 2006) finalmente los restos óseos sufren un proceso que es denominado pulverización y consiste en la pérdida de los constituyentes minerales del hueso. Durante este proce- 
so las piezas óseas se fragmentan y desintegran gradualmente (Trezza 2006). De acuerdo a Galloway (1996) los restos humanos pueden ser clasificados dentro de estas cinco etapas de descomposición:

Figura 10: Etapas en la descomposición de cadáveres humanos.

\section{Procesos conservadores}

Por otro lado se encuentran factores que detienen o hacen lento el proceso de descomposición. Entre ellos se encuentran los siguientes:Figura 11: Procesos conservadores de cadáveres.

Hay tres principales tipos de momificación: a) Momificación natural: producido por factores que actúan solos o combinados como calor, frio, ausencia de aire en el lugar en donde quedó el individuo. B) Momificación intencional: causado por el uso intencionado de las características antes descritas. C) Momificación artificial: producido por una variedad de técnicas entre las que se incluyen la evisceración, el curado con fuego y humo o la aplicación de sustancias embalsamadoras (Sledzik \& Micozzi 1996).

Los elementos culturales son útiles para estimar la antigüedad de los restos humanos. En general es aceptado que el uso de materiales sintéticos se dio a partir de la Segunda Guerra Mundial. Por lo que en tiempos "pre-sintético" los elementos de uso diario estaban hechos de fibras naturales (algodón, lana), metal, madera, hueso, piel y faneras entre otros. Monedas y billetes acuñados en distintos años coexisten dado que su tiempo de uso es bastante prolongado. Medicamentos y alimentos llevan la fecha de caducidad y su tiempo de uso es relativamente más corto. Los periódicos son objetos de un uso aún más breve puesto que su utilidad principal se remite al día en que circula la edición impresa. Estilos de vestimentas y calzado pueden ser útiles indicadores de temporalidad. Las alteraciones culturales y patológicas pueden ser útiles indicadores sobre la naturaleza de los restos humanos.

\section{Restos Expuestos al Fuego}

La cremación de cadáveres, ya sea que se encuentren frescos o en avanzado estado de descomposición, es una práctica que ha sido registrado tanto en situaciones de graves violaciones a los derechos humanos como en casos comunes. Cuando nos encontremos antes restos humanos que han sido expuestos al fuego podemos usar los siguientes términos: a) carbonizados y b) calcinados. Debe quedar en claro que un mismo individuo puede tener partes de su cuerpo carbonizados y otras partes calcinados dependiendo de la atmosfera, la temperatura y al tiempo en que estuvieron expuestos al fuego. Las características de uno y otro son descritas en el siguiente cuadro.

\begin{tabular}{|c|c|c|}
\hline Congelación & Adipocira & Corificación \\
\hline $\begin{array}{l}\text { Para que este proceso ocurra esta } \\
\text { debe ser inmediata y constante } \\
\text { (Trezza 2006). }\end{array}$ & $\begin{array}{l}\text { Tiene aspecto graso untoso o viscoso } \\
\text { tiene coloración blanquecina o } \\
\text { blanco-amarillento de aspecto } \\
\text { jabonoso y de consistencia semisólida } \\
\text { con el característico olor a manteca } \\
\text { rancia. Es blanca cuando produce en } \\
\text { el agua o amarillenta cuando se } \\
\text { produce en terrenos húmedos } \\
\text { (Trezza 2006). }\end{array}$ & $\begin{array}{l}\text { La piel toma las características de un } \\
\text { cuero recién curtido. Es de coloración } \\
\text { gris amarillenta o amarronada } \\
\text { amarillenta de consistencia } \\
\text { aumentada y difícil de cortar (Trezza } \\
2006 \text { ). }\end{array}$ \\
\hline Desecación & Petrificación o calcificación & Fosilización \\
\hline $\begin{array}{l}\text { La putrefacción es reemplazada por } \\
\text { una desecación extrema de los } \\
\text { tejidos producto de la deshidratación } \\
\text { inhibiendo el desarrollo bacteriano } \\
\text { (Trezza 2006). }\end{array}$ & $\begin{array}{l}\text { Es producido por depósitos de sales } \\
\text { calcáreas sobre la estructura } \\
\text { orgánica. }\end{array}$ & $\begin{array}{l}\text { Demora entre miles y millones de } \\
\text { años. Se produce por lo general en } \\
\text { material sedimentario. Su estudio } \\
\text { corresponde a la Paleontología. }\end{array}$ \\
\hline
\end{tabular}

Figura 12: Elaborado en base a Mayne (1996) 


\title{
Naturaleza del Contexto
}

Una vez realizado el registro y análisis del contexto se debe proceder a establecer la naturaleza de los restos humanos y elementos asociados en las siguientes categorías:

Arqueológico: Son aquellos restos y elementos asociados procedentes de tiempos anteriores a la invasión española (hasta aproximadamente 1,532). A esta época también se le conoce como Prehispánica. Entre lo arqueológico y lo histórico se encuentra lo que se conoce como Transicional los cuales son hallazgos excepcionales en el quehacer forense y temporalmente se encuentra en el primer siglo de la presencia hispánica y corresponde a lo que se conoce como descubrimiento y conquista. Es un tiempo en que se producen los primeros mestizajes genéticos y culturales expresándose este último en la cultura material.

Histórico: Inicia desde la invasión española hasta los tiempos actuales. Esta puede ser dividido en Época Virreinal o Colonial (desde aproximadamente 1532 hasta el fin del poder hispánico en 1821) y Época Republicana (Desde 1821 hasta el presente). Dentro de esta última podemos ubicar el denominado Perú Contemporáneo (desde el Gobierno Revolucionario de las Fuerzas Armadas de él Gral. Juan Velazco Alvarado hasta nuestros días)

Forense: Se encuentra en función al interés legal en conocer la identidad de los restos, la existencia tanto de familiares directos como la del perpetrador. Temporalmente se encuentra dentro del Perú Contemporáneo (aproximadamente desde 1968 hasta nuestros días). Se trata de un tiempo que corresponde a lo que últimamente se denomina Pasado Reciente o Pasado Presente que está caracterizado por la existencia de informantes directos que vivieron un determinado suceso.

Indeterminado: No se cuenta con información contextual suficiente.

\section{Agradecimientos}

Expreso mi agradecimiento a Patricia Maita Agurto, Omar Pinedo Pérez y a Gerardo Solf Segura quienes comentaron e hicieron útiles sugerencias al texto inicial. Sin embargo debo dejar constancia que cualquier error de forma y fondo del presente artículo es de única y exclusiva responsabilidad del autor.

\section{BibliografíA}

\author{
ALIAGA ALMELA, Raquel
}

2012 “Términos y conceptos para el estudio de las prácticas funerarias en Arqueología”.

Consultado el 31 de enero del 2016 de file:///C:/Users/FESTRADA/Downloads/Dialnet-TerminosYConceptosParaElEstudioDeLasPracticasFuner-4048996.pdf

\section{ANDRES RUPÉREZ, María Teresa}

2003 "El concepto de la muerte y el ritual funerario en la prehistoria". En: Cuadernos de Arqueología. Universidad de Navarra 11: 13-36.

BACIGALUPO SALINAS, Carlos

2005 “Cap. V: El registro de sitios de entierro. La investigación preliminar antropológica forense en casos de graves violaciones a los derechos humanos". Lineamientos básicos. CENIA. Lima, Perú. 
BUIKSTRA, J. \& UBELAKER, D.

1994 "Standards. For data collection from human skeletal remains". Arkansas Archaeological Survey Research. Series $N^{\circ} 44$, USA.

BROTHWELL, Don

1987 Desenterrando huesos: la excavación, tratamiento y studio de restos del esqueleto humano. Fondo de Cultura Económica. México.

CLARK, M.; WORRELL, M.; PLESS, J.

1996 "Chapter 9: Postmortem changes in soft tissues". Forensic Taphonomy: the postmortem fate of human remains. CRC Press, USA.

COMISION DE LA VERDAD Y RECONCILIACIÓN NACIONAL (CVR)

2003 Plan Nacional de Investigaciones Antropológico-Forenses. Tomo IX. Cuarta Parte: "Recomendaciones de la CVR, hacia un compromiso nacional por la reconciliación”. Lima, Perú.

DUDAY, Henri

1997 Antropología biológica “de campo", tafonomía y arqueología de la muerte. "El cuerpo humano y su tratamiento mortuorio". Malvido, E.; Pereira, G., Tiesler, V. Eds. Centro de Estudios Mexicanos y Centroamericanos, Concejo Nacional para la Cultura y las Artes, INAH. México.

Di MAIO \& DANA, Suzanna

2003 “Capítulo 3: Data de la muerte-descomposición”. Manual de Patología Forense. Díaz de Santos. España.

ESTRADA MORENO, Flavio

2012 “Principios de arqueología forense”. Arqueológicas 29: 53-70. Museo Nacional de Arqueología, Antropología e Historia del Perú.

2013 "El largo camino a la muerte: Apuntes sobre tratamientos pre y postdeposicionales de cadáveres en cementerios contemporáneos en el Perú”. Arqueología y Sociedad 26:395-406. Museo de Arqueología y Antropología. Universidad Nacional Mayor de San Marcos. Lima, Perú.

FONDEBRIDER, Luis; MENDOZA, María Cristina

2001 "Protocolo modelo para la investigación forense de muertes sospechosas de haberse producido por violación de los derechos humanos. Oficina del alto comisionado para los derechos humanos de las Naciones Unidas. Proyecto MEX/00/AH/10. México. Consultado el 24 de enero del 2012 de http://www.pgjdf.gob.mx/temas/4-6-1/fuentes/11-A-8.pdf

GALLOWAY, Alison

1996 “Chapter 8. The process of decomposition: A model from Arizona-Sonoran desert”. Forensic Taphonomy: the postmortem fate of human remains. CRC Press, USA.

JESSEE, E.; SKINNER, M.

2005 “A tipology of mass grave and mass grave-related sites". Forensic Science International 152: 55-59.

KAULICKE, Peter

1997 “La muerte en el antiguo Perú. Contextos y conceptos funerarios: una introducción”. Boletín de Arqueología PUCP. N 1: 7-54. 
KOMAR, Debra; BUIKSTRA, Jane

2008 "Chapter 9: Mass death and international investigations of human rights violations". Forensic Anthropology. Contemporary theory and practice. Oxford University Press. New York.

MAYNE CORREIA, Pamel

1996 "Chapter 18: Fire modification of bone: A review of the literature". Forensic Taphonomy: the postmortem fate of human remains. CRC Press, USA.

QUINTANA, Jordi A.; ALESAN A., Alicia

2003 “Cap. 2: Métodos de recuperación, tratamiento y preparación de los restos humanos”. Paleopatología. La enfermedad no escrita. Isidro,A. y Malgosa, A.Editorial Masson. España.

RAVINES, Roger

1989 “Cap. 4: Excavación”. Arqueología práctica. Editorial Los Pinos E.I.R.L., Lima, Perú.

ROKSANDIC, Mirjana

2002 "Position of skeletal remains as a key to understanding mortuary behavior". En: W.D. Hanglund y M.H. Sorg (Eds.) Advances in forensic taphonomy. Boca Raton.CRC Press.

SLEDZIK, P. \& MICOZZI, M.

1996 "Chapter 31: Autopsied, embalmed, and preserved human remains: distinguish features in forensic and historic contexts". Forensic Taphonomy: the postmortem fate of human remains. CRC Press, USA.

SPRAGUE, Roderick

2005 Burial Terminology. A guide for researchers. Altamira Press. United Kingdom.

MINISTERIO DE JUSTICIA Y DERECHOS HUMANOS

2013 Aprueban Reglamento de la Ley Nº 29986 que modifica el artículo 239 del Código Procesal Penal, aprobado por el Decreto Legislativo $N^{\circ}$ 638; y el artículo $195^{\circ}$ del Código Procesal Penal aprobado por el Decreto Legislativo $N^{\circ}$ 957. Domingo 8 de setiembre 2013.

TREZZA, Fernando Claudio

2006 Data de la muerte. Dosyuna ediciones argentinas. Buenos Aires. Argentina.

UBELAKER, Douglas

2003 “Enterramientos humanos. Excavación, análisis, interpretación”. Munibe, suplemento 24. GEHIGARRIA. ARANZADI. España.

VARGAS-ALVARADO, Eduardo

1991 Medicina forense y deontología médica. Editorial Trillas, México D.F.

WHITE, Tim; FOLKENS, Pieter

2005 "Chapter 6: Anatomical terminology". The human bone manual. Elsevier Academic Press. USA. 
